\title{
The Psychological Mechanisms of Oppression: Empathy, Disgust, and the Perception of Group Membership Alexander Harris, * Philosophy
}

\begin{abstract}
From a psychological standpoint, the oppression and marginalization of certain groups can be understood on the basis of two emotional mechanisms, empathy and disgust. This essay seeks to illuminate how both emotions are heavily modulated by the perception of group membership and how both show the capability to be heavily influenced by social and cultural contexts. This cultural prejudice works by determining what markers of difference (such as skin color or religion) are socially salient, which allows groups to build hierarchies based on those differences that would otherwise remain irrelevant. This paper does not seek to justify group domination as an organic product of psychology, but rather to merely give an account of how the psychological phenomena of disgust and empathy accentuate and collapse, respectively, the borders between people on the basis of in-group and out-group perception. Using the results of psychological tests, the author draws out certain arguments that are philosophically telling as well as politically relevant. Taken together, the social and psychological construction of differences between racial groups in the United States has altered how and when empathy and disgust have been elicited, and has thereby facilitated the reification of extraordinarily oppressive and atrocious group biases into a strict hierarchal system. With this understanding of how group oppression is able to take place on a psychological level we can better understand what can be done to mitigate the negative effects of in-group, out-group interaction.
\end{abstract}

\section{INTRODUCTION}

From a psychological standpoint, the oppression and marginalization of certain groups can be understood on the basis of two emotional mechanisms: empathy and disgust. Both emotions are heavily modulated by the perception of group membership and show the capability to be heavily influenced by social and cultural contexts. This cultural prejudice works by determining what markers of difference (such as skin color or religion) are socially salient, which allows groups to build hierarchies based on those differences that would otherwise remain irrelevant. This paper does not seek to justify group domination as an organic product of psychology, but rather to merely give an account of how the psychological phenomena of disgust and empathy accentuate and collapse, respectively, the borders between people on the basis of in-group and out-group perception. Taken together, the social and psychological construction of differences

\footnotetext{
*Alexander J. Harris is an undergraduate student at the University of Oregon working to complete degrees in both Philosophy and Political Science. His main interests are political and social philosophy (mostly in the Pragmatist tradition of John Dewey), Latin and Native American politics, and modern environmental issues. Alex plans to attend the University of Washington School of Law and someday practice environmental law in either Oregon or Washington. Please send all correspondence to alex.harris24@gmail.com
} 
between racial groups in the United States has altered how and when empathy and disgust have been elicited, and has thereby facilitated the reification of extraordinarily oppressive and atrocious group biases into a strict hierarchal system.

\section{EMPATHY}

Empathy is an affective mechanism that facilitates pro-social motivation and behavior toward in-group members. Empathy allows an individual to vicariously experience the emotions and thoughts of another person without having direct communication with that person. This has served as an aid to understanding another's need as well as a motivating impetus to fulfill that need. This affective mechanism acts as a catalyst for cooperation and coordination amongst individuals, ultimately resulting in the net benefit of the parties involved. Studies show that empathic responses to the perception of pain in another involve an affective response, but not a sensory response of the pain experienced (Singer et al. 1157-1158). Thus, while empathy is commonly compared to stepping into the shoes of another, one never fully occupies these shoes because one cannot literally experience the sensory pain of another person. Nonetheless, empathy builds strong in-group ties that lead to extraordinary displays of altruism and selfsacrifice through bridging the gap between otherwise disparate individuals with strong affective responses.

How exactly does empathy build strong ties among individuals in a group? To answer this question, an important component of empathy must be identified. An individual will experience a greater affective response when observing the pain or suffering of an in-group member than she will experience when observing the pain or suffering of an out-group member. In other words, the intensity of an individual's empathic response to the observance of pain is largely determined by her perception of whether or not the victim is one of her own group (us) or a member of a different group (them). The elicitation of this affective response constructs a bond between the self and the victim, a bond that is very often strong enough to motivate and galvanize the observer into taking action to prevent the further suffering of the victim.

Contreras-Huerta et al. expand on this extraordinary aspect of empathy by comparing the neural empathic responses of perceived pain across racial lines. Their project is organized to answer two simple questions: does racial difference modulate empathic responses to pain, and if so, how does racial difference operate in the modulation of empathy? They attempted to answer these questions by testing the empathic reactions of Caucasian-Australians. The researchers, through a series of affective priming tasks, successfully created a minimal group paradigm, which is merely an artificial group created on a random basis. For example, a minimal group paradigm would be created if a teacher split a classroom full of students in half based on their birthday and then gave one group red hats and the other blue hats. The researchers in the Contreras-Huerta et al. study used this technique to create two groups and primed the participants until they showed strong association with and preferences for the group they were assigned. Once the participants had been primed, they were tested in an fMRI scanner to see if their empathic responses corresponded with the observed pain of in-group and out-group members. Surprisingly, despite the explicit identification with their group just moments before, 
the participants experienced no more neural empathic affect to the observed pain of their ingroup members than they did of the observed pain of out-group members.

Simultaneously, the researchers tested to see if racial biases were present in the reactions of the participants. Prior to the fMRI tests, the participants showed no aversion or preference to racial groups, but only to the groups to which they had been primed (groups created by the minimal group paradigm); however, the fMRI scans revealed that the observance of pain across racial lines resulted in a significantly diminished empathic response compared to the response of observed pain within racial categories. To further clarify, when Australian participants viewed Chinese participants getting poked with a needle, the Australian viewers experienced less empathic affect than they did when they viewed a fellow Australian getting poked with a needle. From these results, Contreras-Huerta et al. argue, "Race has been demonstrated as a feature impossible to ignore in facial processing, even when race is implicit and not relevant to the participant's task. Thus, it is possible that race may cause an automatic and bottom-up bias in empathic neural activation of pain" (Contreras-Huerta et al. 8).

The authors of this experiment posit that race may likely operate at a more basic level than broader social distinctions. My objection to this interpretation is twofold. Firstly, they base their conclusions on the fact that even though the participants of the survey showed clear group biases before the fMRI tests, the test results showed no difference in perceived pain across their primed group lines. Since the assignment to these groups was arbitrary and ultimately noncommittal, I argue that the psychological affect associated with the membership of these fabricated groups was necessarily weak. The saliency of a social group is likely to be more pronounced if there is historical and symbolic baggage associated with the group and if that baggage is constitutive of group members' identity. Since the minimal group paradigm constructed by the researchers comes with no such baggage, it cannot be representative of other social groups, groups laden with symbolism and historic ties. Secondly, Contreras-Huerta et al. argue that race has such a deep impact on empathic responses because of the saliency of its physical cues (i.e. skin color), whereas the group membership of the participants was not associated with any physical cue. I argue that race has such a potent influence on empathic responses only because it has historically been rendered as a socially significant indicator of group membership on the basis of these physical cues. In other words, skin color is not just a spectrum of shades, but also a spectrum of social indicators that have historically, and still do, have an enormous impact on how people are organized materially, economically, politically, and culturally. Therefore, these phenotypical markers come with certain social baggage that causes the individual to psychologically determine in-group, out-group members, which thereby modulates her empathic responses. In a word, racial bias in empathic responses is not an organic, inevitable reality (bottom-up empathic discrimination), but instead an informed and learned bias that applies to all in-group, out-group interactions (top-down empathic discrimination).

To prove that group membership, and not race, is the paramount factor in determining the degree of empathic response, it is necessary to consider what effect real-world social categories, such as religion or culture, have on individuals. When Emile G. Bruneau et al. conducted an 
fMRI test on the elicitation of empathy in Arabs and Israelis, the scans not only revealed a significantly diminished degree of empathic affect in the individual who observed pain in a member of the opposite group, but also more involvement in the prefrontal cortex. This region of the brain is responsible for discriminating between conflicting thoughts and then making decisions in accordance to the superior thought. This suggests that in some instances, the prefrontal cortex informs the physiological empathy system of the victim's out-group status, resulting in the weaker elicitation of empathy. This kind of "top-down" modulation of the empathic response illustrates that the group categories have cognitive significance and play an integral role in determining the empathic reaction.

To push this further, imagine a world where people are born with much greater phenotypical diversity within racial groups than usual.. In this world, skin color, hair density, eye shape, and lip size would all be equally as physically salient as they are in real life; however, they would not carry any social significance. Since physical differences would not line up with social group categories, they would have as much social significance as eye color or belly button shape have in our world. Because, in our world, race has historically had such social saliency, and since none of us have ever known the world without such importance placed on phenotype, race is psychologically treated as an indicator of group membership. I argue that this treatment is not "natural" or "inevitable", but rather somewhat arbitrary and historically contingent. Therefore, this kind of psychological process in only "bottom-up" in the sense that it takes place at a very subconscious level, and not in the sense that we are biologically hardwired to feel strong aversions to different skin colors. Therefore, those group categories, such as race, that carry social significance and physically salient cues modulate and regulate the empathic reaction elicited in members of different groups. Since racial categories in the United States have always had major social, political, legal, and moral significance, and since these categories have been based on phenotypical markers, the actual empathy experienced by white Americans towards racial minority groups has likely been modulated and diminished.

From this view, it may seem appropriate to assume that one's empathy is modulated by the difference between herself and the victim she observes; however, it is not the difference between individuals that modulates neural empathic responses, but merely the perception of difference that is responsible. This perception is highly susceptible to culturally acquired prejudice, prejudice which is very often not the accidental product of social interactions, but rather the product of a cold, calculated agenda to dominate and oppress. Indeed, the dominant group generally chooses which differences should be considered socially salient and ignores those differences that hinder their agenda to control. Thus, skin color is rendered as a telling social characteristic, a sign of fundamental difference from the "neutral" white man, and his inferiors. By depicting racial differences as socially relevant indicators, the dominant group becomes convinced of these differences, prompting a recalibration of their empathic ties to the lesser group. Their dearth of empathy towards out-group members further confirms their conviction of their differences, for now in addition to telling themselves these differences exist they also feel the dissimilarities. 
The fade in empathy for those who seemingly belong to different groups contributes to propagate and nourish rigid social hierarchies, and thus is dangerous to social egalitarianism. Situations in which racial minorities undergo severe suffering and misery fail to elicit strong affective responses in the dominant majority group. The dearth of affective content results in a lack of motivation or desire to change the conditions that gave rise to the suffering, especially when those conditions are economically beneficial to the dominant group. Unfortunately, those who are a part of the dominant group are likely to be in a position of power to prevent the suffering of minority groups. However, the dominant group lacks the affective response necessary to act altruistically towards other groups and thus generates a deep sense of apathy that bleeds into the political and social centers of power. This indifference allows for the justification of extremely unequal policies that perpetuate and maintain the systemic modes of dominance that originally produced the racial differences in the first place. The feedback loop is completed when oppressive policies breed tangible, material inequalities that accentuate the differences between racial groups and further the fade in empathy towards these groups.

A natural counterargument to the claims made thus far is that people do not derive their motivation to act morally from affect, but rather rely almost exclusively on general moral ideals that are more subservient to the rules of logic. In ardent opposition to this counterclaim is a mountain of evidence arguing that affect plays an extraordinarily important role in motivating or demotivating individuals to act morally. Paul Slovic et al. argue that in cases of charity, "compassion shown towards victims has been found to decrease as the number of individuals in need of aid increases, identifiability of victims decreases, and proportion of victims helped declines" (Slovic et al. 4). Their study starts by asserting that there is no logical reason to give less money to a group of six children than to give to one child, for, if anything, logic would demand that the group of six should get more because there is six times the need. Slovic et al., however, show that since the affect is greater if just one identified child is helped, people give more money on average to one child than to the group of six. In a similar study, Slovic et al. demonstrate that in cases of charity, providing information about those who cannot be helped will demotivate the individual from helping those she can help. The negative affect associated with the children not helped induces a sense of pseudo-inefficacy great enough to counteract the positive affect that would be achieved by helping those other children that can be helped (Slovic et al. 4) These studies illustrate how affect, however illogical, plays a crucial role in motivating people to act morally. While these studies do not demonstrate racial bias in empathic responses, they give evidence to the argument that the fade in empathic affect across racial lines must account for a major fade in motivation to act altruistically towards those racial out-groups.

\section{DISGUST}

Disgust is generally believed to have played an evolutionary role in keeping communities free of contamination and disease; however, there is disagreement about the exact evolutionary role of social disgust. One theory, as developed by Martha Nussbaum, argues that social disgust has served to reconcile our mortal, animal bodies with our desire to live forever. Nussbaum posits: 
So powerful is the desire to cordon ourselves off from our animality that we often don't stop at feces, cockroaches, and slimy animals. We need a group of humans to bind ourselves against, who will come to exemplify the boundary line between the truly human and the basely animal. If those quasi-animals stand between us and our own animality, then we are one step further away from being animal and mortal ourselves. (107)

In this quote, Nussbaum identifies disgust as a mechanism used to anchor ourselves as human beings by identifying and isolating the non-human. While this view is extremely limited in its ability to account for the evolutionary development of social disgust, it does illustrate how disgust is necessarily dehumanizing to some while simultaneously humanizing to others. Nussbaum correctly identifies this universally human phenomenon as an emotion relating to the physicality of the body, a kind of obsession with purity and health. Disgust, therefore, uses dehumanizing means, such as slavery and extermination, to cleanse the body politic of any deviation from humanity.

Daniel Kelly, in his book, Yuck! The Nature and Moral Significance of Disgust, develops an alternative and superior model of disgust. His project identifies the original function of disgust as a mechanism that triggers the expulsion of toxic poisons and signals the threat of potentially contagious diseases. According to Kelly, emotional responses felt in disgusting situations protect us from becoming entangled with parasites and poisons that might be dangerous. This emotion came to involve a whole cluster of specific reactions such as the gape face, quick withdrawal of the body (especially of the face and mouth), and certain cognitive reactions such a sense of offensiveness and contamination. These reactions all served a biological purpose, but over the course of many thousands of years eventually became associated with disgusting situations, and thus developed a communicative function. This was useful for groups that wanted to ensure the health of the entire community so that they could avoid the spread of disease.

Kelly argues that since the same mechanisms that produce the emotion are also at work in the recognition of the emotion, "not only are people able to naturally recognize a gape as an expression of disgust, but doing so often involves the extra step of actually becoming disgusted oneself” (Kelly 2011. Pg 66). Thus, disgust is highly empathic and, ironically, extremely contagious. While the reaction and recognition of disgust are universal and innate functions that all people share, the elicitors of disgust are highly variable and are largely determined by social norms and susceptible to social learning. What accounts for the wide variety of disgust elicitors? Shouldn't we expect all human beings to be disgusted by the same disgusting things? From an evolutionary standpoint, disgust has developed to be susceptible to social learning because human beings have historically been such a nomadic species. The requirements of adapting to new environments (learning what is and is not safe to eat, drink or touch, and communicating that knowledge to others) have been paramount in the success of the human species.

But what gives disgust its moral and social orientation? Why has disgust been applied to the behavior of human beings? Kelly argues that at some point, the emotion had to be directed at specific groups of human beings infected with dangerous diseases. He argues, "the importance of socially acquired information about the specific poisons and parasites in the local habitat ... 
helped shape an acquisition system that was highly flexible. This combination of features left the emotion susceptible to accruing new auxiliary functions, particularly in the social domain" (Kelly 116). Kelly then argues that because disgust is the perfect candidate for motivating the strict adherence to social norms of the in-group and for punishing those who violate the norms (likely members of the out-group), the emotion was then co-opted to maintain these social norms. The maintenance of these norms was crucial for the survival of the human species, and was only possible through motivating each individual in a group to respect and comply with the norms.

Kelly argues that the obsession with norm unanimity further facilitated the coordination between individuals, which resulted in the benefit of the entire community. Disgust interpreted arbitrary ethnic markers (such as skin color) to have socially relevant meaning. Thus treating those ethnic markers as "an external, physical, and observable indicator of an underlying set of internal, psychological, and unobservable dispositions, namely, the beliefs, values, and clusters of social norms endemic to one particular tribe..." (Kelly 112). Disgust began to operate on the premise that the greater the similarity in values and norms, the more likely another is to cooperate, and since racial differences were thought to be telling of values and norms, racial differences were interpreted to be indicators of cooperativeness. Therefore, strong racial-group animus was formed and the encounter of racially different groups was likely to elicit social disgust. Once again, aversions to racial out-groups are not innate but rather were created through a process of attributing social meanings that operated as an indicator of group membership and cooperativeness to certain physically salient features (such as skin color).

Social disgust is elicited in a very different way than the original emotion of disgust, as the former is usually concerned with the protection of social norms and values whereas the latter is concerned with biological preservation. However, both forms of disgust produce the same cluster of emotional and physical reactions. Social disgust has communicative meaning and social significance. Since disgust has empathic capabilities, disgust elicited by out-group behavior or appearance is easily communicated, understood, and spread to fellow in-group members. The infectious capabilities of disgust combine with its visceral affective response to produce a widespread motivation in in-group members to isolate or eliminate members of the out-group. Such a response is likely to reify ethnocentrism and xenophobia into such atrocities as segregation, indiscriminate violence, and genocide. Therefore, by motivating people to both comply with social norms and punish those who violate those norms, disgust encourages and facilitates the dehumanizing treatment of racial minority groups.

While Kelly's work on disgust offers a reasonable account of the origins and co-option of social disgust, he says little about how disgust has been deliberately co-opted by human beings as a tool of rhetoric. Hitler famously compared Jews to vermin and maggots before and during World War II to mobilize a fierce sense of anti-Semitism. Is this rhetorical technique unique to mid-20 ${ }^{\text {th }}$ century Germany? Surely it is not, judging by the comments of Israeli leaders such as Miri Regev, who stated the African immigrants in Israel "are a cancer in our body", a comment which over half of Israelis agree ("The Peace Index"). The recent comment made by Ugandan President Yoweri Museveni displays a similar group attribution of disgust, justifying the passage 
of new, bellicose laws against homosexuals by saying: "They're disgusting. What sort of people are they?" (Abedine). Invoking disgust as a rhetorical device to manipulate public opinion or to justify hostile group animus appears to be a worldwide phenomenon.

In an analysis of different pieces of rhetoric that have been used to incite disgust in the public over the years, there seems to be a very common technique utilized: bodily metaphors. By comparing a group of people to diseases, insects, vermin, parasites, or feces, the speaker is able to effectively elicit a strong feeling of disgust in her listeners. Even though the listeners know that the out-group is not a "cancer" or "parasite", the rhetoric successfully conflates the original feelings of disgust with those co-opted feelings of social disgust, resulting in the motivation to handle the elicitors of the disgust as if they are actually diseased and infectious. Another potent tool is the utilization of the strong emotional power of sexuality by comparing the infiltration of new out-groups to the rape of society. This is also often accompanied with portraying the outgroup as hypersexual and animalistic, effectively causing the in-group to have genuine worries of sexual violence. Thus, the close relationship between the obsession of biological purity and that of social purity has allowed rhetoric to conflate the two, causing for a more dramatic affect and thus a stronger motivation to act violently.

In her essay Genocidal Language Games, Lynne Tirrell explains how hateful speech acts had an especially strong effect in evoking fear and disgust that motivated and justified the violence perpetrated by Hutus against Tutsis in the 1994 Rwanda Genocide. The derogatory terms with the most significance were "inyenzi", which is Kinyarwanda for "cockroach", and "inzoka", which is Kinyarwanda for "snake". In addition to accentuating the "us" and "them" distinctions, these terms rendered the Tutsis as subhuman animals, which effectively eliminated their membership in the moral community. Tirrell identifies the metaphorical significance of the term "cockroach" when she states, "cockroaches are pests, dirty, ubiquitous, multiply rapidly, are hard to kill, ought to be killed, show emergent tendencies when in groups, are resilient, (and) carry diseases" (200). Snakes, on the other hand, are generally treated with extreme caution and thus usually beheaded immediately. In fact, in Rwanda, the beheading of a snake is a certain kind of rite of passage for young boys, and thus the execution of a snake is a conferment of communal trust and pride (Tirrell 176). Tirrell argues that the comparison to insects and snakes is no accident, but instead a deliberate attempt to incite strong feelings of disgust and transform those feelings into the performance of violence. Upon considering Tirrell's arguments about the reification of disgust-laden language into performative violence, Kelly's evolutionary account of disgust, and words from leaders around the world, it becomes apparent that disgust plays a very active and palpable role in shaping in-group and, out-group distinctions. Once these distinctions are created, this destructive emotion wastes no time in motivating its hosts to eliminating out-group members, either socially (i.e. shunning) or physically (i.e. extermination).

\section{CONCLUSION}

It is evident that the oppression of certain groups can be largely understood on the basis of two emotional mechanisms, empathy and disgust. Both emotions are heavily influenced and affected by the perception of group membership, a perception that is easily manipulated and 
transmitted through the collective consciousness. Empathy and disgust developed to maintain and bolster the welfare of the in-group. Empathy encourages prosocial behavior within the group and disgust discourages prosocial behavior towards the out-group. Disgust also enhances group separation on the basis of what is considered socially relevant, which allows group bias in the elicitation of empathy to grow. Physically salient differences, such as skin color, have been interpreted to have social and moral significance, allowing cultural prejudice to build hierarchies based on these physical differences. Since the perception of in-group and out-group membership has served as the basis for how disgust accentuates and how empathy collapses the borders between people, perception must therefore be altered if the present racial relations in the United States are to be improved. To prevent the reification of oppressive and atrocious group biases into strict hierarchal systems, group membership must be extended to include people across socioeconomic and racial lines. By including more people into one's in-group, the negative effects of social disgust will be largely avoided and the potential positive effects of empathy will be communally enjoyed.

\section{REFERENCES}

Abedine, Saad. "Ugandan tabloid prints list of 'homosexuals'." CNN. Cable News Network, 25 Feb. 2014. Web. 19 Oct. 2014. <http://www.cnn.com/2014/02/25/world/africa/ugandaanti-gay-law/>.

Bruneau, E. G., N. Dufour, and R. Saxe. "Social Cognition in Members of Conflict Groups: Behavioural and Neural Responses in Arabs, Israelis and South Americans to Each Other's Misfortunes."Philosophical Transactions of the Royal Society B: Biological

Sciences 367.1589 (2012): 717-730. Print.

Contreras-Huerta, Luis Sebastian, Katharine S. Baker, Katherine J. Reynolds, Luisa Batalha, Ross Cunnington, and Wang Zhan. "Racial Bias in Neural Empathic Responses to Pain." PLoS ONE 8.12 (2013): e84001. Print.

Kelly, Daniel R.. Yuck! The Nature and Moral Significance of Disgust. Cambridge, Mass.: MIT Press, 2011. Print.

Nussbaum, Martha Craven. Hiding from Humanity: Disgust, Shame, and the Law. Princeton: Princeton University Press, 2004. Print.

Singer, Tania, Ben Seymour, John O'Doherty, Holger Kaube, Raymond Dolan, and Chris Frith. "Empathy For Pain Involves The Affective But Not Sensory Components Of Pain." Science 303.5661 (2004): 1157-1162. Print.

Slovic, Paul, Daniel Vastfjall, and Marcus Mayorga. "Whoever Saves One Life Saves the World: Confronting the Challenge of Pseudoinefficacy." Genocide Prevention Initiative. University of Oregon. July 2014. Web. 26 Sept. 2014 
Tirrell, Lynne. "Genocidal Language Games." Speech and Harm: Controversies Over Free Speech. Eds. Ishani Maitra and Mary Kate McGowan. Oxford: Oxford University Press, 2012. 174-221. Print.

"The Peace Index." The Peace Index. N.p., n.d. Web. 19 Oct. 2014.

<http://www.peaceindex.org/indexMonthEng.aspx?num=242>. 